\title{
Potencial Alelopático de Soluções de Solo Cultivado com Brachiaria brizantha: EFEITOS SOBRE A GERMINAÇÃo DE GRAMÍNEAS Forrageiras e Plantas Daninhas de Pastagens ${ }^{1}$
}

\author{
Allelopathic Potential of Solutions of Soils Cultivated with Brachiaria brizantha: Effects on \\ Some Pasture Grass and Weeds Seeds
}

MARTINS, D. ${ }^{2}$, MARTINS, C.C. ${ }^{2}$ e COSTA, N.V. ${ }^{3}$

\begin{abstract}
RESUMO - O objetivo desta pesquisa foi obter informações que possam favorecer o entendimento da atuação dos compostos alelopáticos sobre o banco de sementes do solo e sobre a seleção de plantas invasoras e indicar espécies que favoreçam a renovação dos pastos. Assim, soluções de solo de uma área de pastagem de Brachiaria brizantha cv. Marandu formada há mais de cinco anos foram extraídas para avaliar os efeitos alelopáticos dessa espécie sobre a germinação, a dormência de sementes e o vigor de plântulas de B. brizantha cv. Marandu, Panicum maximum cv. Tanzânia, Sida rhombifolia e Peschiera fuchsiaefolia. O experimento foi instalado e conduzido no Laboratório de Matologia do Departamento de Produção Vegetal da FCA/UNESP - campus de Botucatu-SP. O substrato de germinação foi umedecido com $12 \mathrm{~mL}$ dos seguintes tratamentos: solução do solo de uma área cultivada com $B$. brizantha; solução do solo de uma área sem $B$. brizantha (mata nativa); água destilada; solução de polietilenoglicol com potencial osmótico idêntico ao da solução do solo sob $B$. brizantha; e solução de polietilenoglicol com potencial osmótico idêntico ao da solução de solo de uma mata nativa. A porcentagem de sementes normais, mortas, anormais e dormentes de $B$. brizantha não foi influenciada por nenhuma das soluções testadas, o que evidencia a não-ocorrência de efeito auto-alelopático. Foram verificados possíveis efeitos alelopáticos negativos sobre a porcentagem e velocidade de germinação de $P$. maximum cv. Tanzânia e sobre o crescimento radicular de $S$. rhombifolia. Esta última também se mostrou sensivel ao efeito alelopático da solução de solo de mata, que promoveu redução no crescimento radicular. $P$. fuchsiaefolia não foi afetada por nenhuma das soluções testadas.
\end{abstract}

Palavras-chave: alelopatia, plantas invasoras e sementes.

\begin{abstract}
Soil solutions were extracted from a pasture area, formed with Brachiaria brizantha $c v$. Marandu for over 5 years, to evaluate the allelopathic effects of this pasture grass on seed germination, dormancy, mortality, percentage of normal plants, germination velocity and shoot growth of B. brizantha $c v$. Marandu and Panicum maximum $c v$. Tanzânia and pasture weeds Sida rhombifolia and Peschiera fuchsiaefolia. The germination substrate was humidified with $12 \mathrm{~mL}$ of the following treatments: Soil solution from an area cultivated with B. brizantha; soil solution from an area without B. brizantha (Forest); distilled water and Polyethylene glycol solution (molecular weight $=6000$ ), combined with solutions from soil with and without B. brizantha. Allelopathic effects occurred at germination velocity index for P. maximum Tanzânia. For shoot growth, both pasture and forest soil solutions had a negative effect on root growth of $\mathbf{S}$. rhombifolia. No effects were observed for $\boldsymbol{P}$. fuchsiaefolia.
\end{abstract}

Keywords: allelopathy, weeds and seeds.

1 Recebido para publicação em 30.6.2005 e na forma revisada em 24.2.2006.

2 Prof. Dr., Dep. Produção Vegetal-Agricultura, Faculdade de Ciências Agronômicas, Universidade Estadual Paulista FCA/UNESP, Caixa Postal 237, 18603-970 Botucatu-SP. <dmartins @ fca.unesp.br>. ${ }^{3}$ Eng.-Agr., aluno de Pós-graduação, Dep. Produção Vegetal-Agricultura, FCA/UNESP.

Planta Daninha, Viçosa-MG, v. 24, n. 1, p. 61-70, 2006 


\section{INTRODUÇÃO}

O estudo da alelopatia em pastagens pode ser complexo, pois o pisoteio e o pastejo seletivo ou excessivo, bem como o empobrecimento e a compactação do solo, podem exercer pressão seletiva sobre as espécies de pastagens, a qual pode ser interpretada como resultante de efeito alelopático. Na prática, áreas formadas com Brachiaria spp. permanecem produtivas por dois a três anos e, após esse período, apresentam sinais de degradação (Rodrigues \& Reis, 1994), como o surgimento de áreas com solo descoberto.

A redução da capacidade de suporte das pastagens em curto período de tempo, a introdução de novas espécies e o lançamento de novos cultivares estimulam os produtores a procurar forrageiras para substituir aquelas existentes em suas propriedades. No entanto, a renovação do pasto é dificultada pela presença de sementes da pastagem anterior, as quais surgem como espécies infestantes da nova pastagem, após as operações de preparo do solo (Rodrigues et al., 1993; Rodrigues \& Reis, 1994).

Na pastagem sem renovação, as sementes da forrageira não germinam, mesmo estando na superfície, em áreas de solo desprovido de vegetação e na presença de água. Há casos em que amostras de solo coletadas nos primeiros $10 \mathrm{~cm}$ de profundidade, em área de pastagem degradada de Brachiaria brizantha cv. Marandu, apresentaram um banco de sementes no solo com 380 sementes puras viáveis por $\mathrm{m}^{2}$ (Embrapa, 1991).

As pesquisas utilizando extratos aquosos de plantas indicam a existência de potencial alelopático de Brachiaria brizantha cv. Marandu sobre a germinação e o desenvolvimento de leguminosas forrageiras (Stanizio et al., 1991; Almeida, 1993; Carvalho, 1993) e de plantas daninhas de pastagem, como Desmodium adscendens, Sida rhombifolia e Vernonia polyanthes (Souza Filho et al., 1997). Contudo, experimentos em que se utilizou solução do solo estariam mais próximos das condições encontradas em campo (Souza, 1994; Castro et al., 1997; Velini et al., 1997). A identificação de forrageiras com potencial alelopático e o conhecimento dos mecanismos pelos quais elas exercem seus efeitos no ambiente apresentam grande importância, por propiciarem um manejo mais adequado dessas plantas, com o objetivo de aumentar a produtividade e a persistência das pastagens (Rezende et al., 2003).

O conhecimento do potencial alelopático de Brachiaria brizantha é importante para entender o processo de degradação de pastos formados com essa espécie, a fim de direcionar a adoção de práticas agronômicas que permitam a reforma ou o estabelecimento de outras espécies de gramíneas forrageiras e para entender o efeito da solução do solo sobre o banco de sementes de gramíneas forrageiras.

Portanto, o presente trabalho teve como objetivo avaliar os possiveis efeitos alelopáticos de soluções de solo cultivado com Brachiaria brizantha cv. Marandu sobre a germinação, a dormência de sementes e o crescimento de algumas plantas forrageiras (Brachiaria brizantha cv. Marandu e Panicum maximum cv. Tanzânia) e de plantas daninhas de pastagens (Sida rhombifolia e Peschiera fuchsiaefolia).

\section{MATERIAL E MÉTODOS}

O experimento foi instalado e conduzido no Laboratório de Matologia do Departamento de Produção Vegetal da FCA/UNESP - campus de Botucatu-SP. Foram realizadas coletas de solo, com auxílio de trado, na camada de 0 a $10 \mathrm{~cm}$ de profundidade, na região do município de São Manoel-SP, em uma área de pastagem sob solo arenoso formada há cinco anos com $B$. brizantha. As amostras de solo foram acondicionadas em caixa de isopor contendo gelo e transportadas para o laboratório, sendo posteriormente peneiradas com a finalidade de retirar restos vegetais não-decompostos; em seguida, foram acondicionadas em sacos plásticos e armazenadas em freezer a uma temperatura de $-18{ }^{\circ} \mathrm{C}$. Realizou-se a análise química da amostra do solo coletado na área com $B$. brizantha. O mesmo procedimento de coleta de solo foi adotado em uma área adjacente à pastagem, em um local de mata nativa.

O solo sob mata apresentou 83, 0,0 e 17\% de areia, silte e argila, respectivamente. Os resultados da análise química evidenciaram $\mathrm{pH}$ em $\mathrm{CaCl}_{2}$ de 4,3; teores de matéria orgânica de $34 \mathrm{~g} \mathrm{dm}^{-3}$; CTC de 61 e P de 7 mg dm" 
valores de $1,5,8$ e 5 para $\mathrm{K}, \mathrm{Ca}$ e $\mathrm{Mg}$, respectivamente; e saturação por bases de $23 \%$. O solo sob pastagem de $B$. brizantha apresentou $87,0,0$ e $13 \%$ de areia, silte e argila, respectivamente. Os resultados da análise química evidenciaram $\mathrm{pH}$ em $\mathrm{CaCl}_{2}$ de 5; teores de matéria orgânica de $20 \mathrm{~g} \mathrm{dm}^{-3}$; CTC de 34 e P de $11 \mathrm{mg} \mathrm{dm}^{-3}$; valores de 1,8 e 5 para $\mathrm{K}$, Ca e $\mathrm{Mg}$, respectivamente; e saturação por bases de $40 \%$.

A solução do solo foi extraída por meio de centrifugação, utilizando-se a metodologia desenvolvida por Velini (1996), modificada. A cada processamento da amostra, foram extraídos $16 \mathrm{~mL}$ de solução do solo. As soluções do solo foram acondicionadas em frascos de vidro, na cor âmbar, hermeticamente fechados, identificadas e armazenadas em freezer $\left(-18^{\circ} \mathrm{C}\right)$, para posterior análise do potencial osmótico e uso nos testes de germinação e de crescimento de plântulas.

Medidas de pH e condutividade elétrica foram realizadas para as diferentes soluções testadas, sendo 7,77 (pH) e 705 Ps (condutividade); $7,18(\mathrm{pH})$ e $406 \mathrm{Ps}$ (condutividade); e $6,8(\mathrm{pH})$ e 3 Ps (condutividade), para as soluções de solo retiradas da área com B. brizantha, com mata nativa e da água destilada, respectivamente. Os potenciais osmóticos encontrados para as soluções retiradas da área com $B$. brizantha e com a mata foram de 58,5 e $56,5 \mathrm{mmol} \mathrm{kg}^{-1}$, respectivamente.

Foram avaliadas no estudo as sementes das espécies forrageiras B. brizantha cv. Marandu e $P$. maximum cv. Tanzânia, bem como as seguintes espécies daninhas de pastagens: Sida rhombifolia e Peschiera fuchsiaefolia. A instalação de um teste suplementar de referência de potencial alelopático foi feita utilizando-se sementes de alface do cultivar Great Lakes 366. Os testes de germinação foram conduzidos em caixas gerbox, acondicionadas em câmaras de germinação, com 50 sementes em quatro repetições, sob temperatura alternada de 15$35{ }^{\mathrm{R}} \mathrm{C}$ para as gramíneas forrageiras (Brasil, 1992); para a alface, sob temperatura constante de $20{ }^{\mathrm{R}} \mathrm{C}$, sem luz, sobre duas folhas de papelfiltro; e, para as plantas daninhas, sob temperatura alternada de $20-25{ }^{\mathrm{R}} \mathrm{C}$. As sementes foram mantidas na ausência de luz, a fim de evitar a fotodegradação dos possíveis compostos alelopáticos presentes na solução de solo.
O substrato de germinação foi umedecido com 12 mL dos seguintes tratamentos: solução do solo da área cultivada com B. brizantha; solução do solo da área sem $B$. brizantha (mata); água destilada; solução de polietilenoglicol com potencial osmótico idêntico ao da solução do solo sob B. brizantha; e solução de polietilenoglicol $(\mathrm{PM}=6000)$ com potencial osmótico idêntico ao da solução de solo de mata nativa.

A contagem das plântulas ocorreu em dias alternados, dos 3 aos 7 e 9 dias para alface e $S$. rhombifolia, respectivamente; dos 4 aos 10 dias para $B$. brizantha e $P$. maximum; e dos 11 aos 19 dias para $P$. fuchsiaefolia. Ao final desses períodos foram calculadas as porcentagens de germinação (plântulas normais), de plântulas anormais (Brasil, 1992), e as sementes não-germinadas foram submetidas ao teste de tetrazólio, para identificação das sementes dormentes ou mortas, seguindo a metodologia proposta por Brasil (1992) e Souza (1994). O Î́ndice de Velocidade de Germinação (IVG) foi realizado conjuntamente com o teste de germinação, determinado segundo critério estabelecido por Maguire (1962).

O comprimento de plântulas foi calculado com quatro repetições de 25 sementes, colocadas em papel-toalha umedecido com duas vezes o peso do papel em água ou solução, e conduzido à temperatura constante de $25{ }^{\mathrm{R}} \mathrm{C}$ em câmara de germinação. O comprimento (cm) da parte aérea (colo-ápice da plúmula), da radícula (colo-meristema radicular) e do total da plântula (ápice da plúmula-meristema radicular) foi mensurado com auxílio de uma régua, diariamente dos dois aos cinco dias após a semeadura para $B$. brizantha e dos três aos cinco dias para $P$. maximum. Para P. fuchsiaefolia a mensuração foi em dias alternados, dos 15 aos 21 dias após a semeadura. Para as sementes de S. rhombifolia e L. sativa foram realizadas mensurações das 48 até 84 horas após a semeadura em intervalos de 12 horas. Foi considerada, para o cálculo da média de cada repetição, a população total de sementes.

O delineamento experimental utilizado foi o inteiramente casualizado, com quatro repetições. Os dados foram submetidos à análise de variância pelo teste $\mathrm{F}$, e as médias, comparadas pelo teste $\mathrm{t}(\mathrm{p}<0,05)$. 


\section{RESULTADOS E DISCUSSÃO}

Na Tabela 1 estão apresentados os resultados dos efeitos das diferentes soluções de solo sobre o teste de germinação e sobre o crescimento de plântulas de $B$. brizantha.

Os resultados de IVG indicam que as soluções de solo da pastagem e da mata não influenciaram a velocidade de germinação de $B$. brizantha, uma vez que os dados obtidos foram semelhantes aos da água destilada. As sementes colocadas para germinar em soluções de PEG foram superiores à dos demais tratamentos, provavelmente devido a um efeito de revigoramento propiciado por estas soluções, que podem ter favorecido um processo de condicionamento osmótico das sementes de B. brizantha (Suñé et al., 2002).

O agente osmótico polietilenoglicol (PEG) possui elevado peso molecular, não é eletrolítico, não penetra nas células, além de não apresentar toxicidade, sendo utilizado em experimentos que avaliam os efeitos do estresse hídrico sobre a germinação de sementes (Perez et al., 2001). Assim, o agente osmótico polietilenoglicol utilizado pode ter minimizado os efeitos negativos do excesso de água inicialmente durante a germinação das sementes e explicar os maiores valores obtidos nas soluções com PEG.

A porcentagem de sementes normais, mortas, anormais e dormentes não foi influenciada por nenhuma das soluções testadas, o que evidencia a não-ocorrência de efeito auto-alelopático. O valor médio de sementes germinadas de $B$. brizantha na solução de água destilada foi em torno de $79,75 \%$, enquanto nas soluções de solo da pastagem e da mata foram obtidos os maiores valores, com médias de 85,50 e $81,75 \%$, respectivamente.

No estudo do crescimento das plântulas de $B$. brizantha (Tabela 1) verifica-se que, de modo geral, não ocorreu efeito pronunciado sobre o comprimento da radícula, da parte aérea e da planta como um todo. Entretanto, as soluções de PEG (pastagem) e PEG (mata) apresentaram os maiores comprimentos da radícula e os menores comprimentos da parte aérea, com médias na ordem de 4,09-1,25 e 4,56-1,61 cm, respectivamente, ao final do experimento, o que não caracterizou possiveis efeitos alelopáticos.
Na Tabela 2 estão apresentados os resultados dos efeitos das diferentes soluções de solo sobre o resultado do teste de germinação de $P$. maximum cv. Tanzânia em caixas gerbox e os efeitos sobre o crescimento das plântulas sob papel-toalha.

Observa-se que os resultados do IVG apresentados pelas soluções de solo da pastagem e da mata foram inferiores e estatisticamente diferentes, quando comparados com aqueles obtidos pelos tratamentos de água destilada e das soluções de PEG. Da mesma forma, a porcentagem de sementes normais também foi influenciada pelas soluções de solo da pastagem e da mata. No entanto, o tratamento com a solução de solo de mata não diferiu do tratamento em que se simulou o potencial osmótico da sua solução PEG (mata). Contudo, redução de 9,25\% de sementes normais foi verificada com a aplicação da solução de solo da mata em relação à solução PEG (mata), consistindo em valores expressivos.

Desse modo, pode-se afirmar que ocorreram efeitos alelopáticos sobre o IVG das soluções de solo da pastagem e da mata sobre a germinação de $P$. maximim Tanzânia. A porcentagem de sementes mortas e anormais, de modo geral, foi influenciada pelas soluções testadas, ao passo que a porcentagem de sementes dormentes não apresentou diferenças significativas entre os tratamentos. A solução de solo de pastagem propiciou $21,50 \%$ de sementes normais de $P$. maximum cv. Tanzânia, enquanto as soluções de água destilada e de PEG (pastagem) mostraram valores na ordem de 38,25 e $46,50 \%$, respectivamente, não diferindo estatisticamente do tratamento de água destilada (43,75\%).

No teste de avaliação do crescimento da radícula, da parte aérea e da planta toda (Tabela 2), nota-se que nenhum dos tratamentos testados foi influenciado, evidenciando que os possiveis compostos alelopáticos envolvidos atuam sobre a viabilidade da semente e que, se ocorrer a germinação, eles não mais influenciariam as estruturas de crescimento da planta.

Na Tabela 3 encontram-se os resultados dos efeitos das diferentes soluções de solo sob o teste de germinação de $S$. rhombifolia em caixas gerbox e dos efeitos sobre o crescimento das plântulas sob papel-toalha. 
Tabela 1 - Efeito de diferentes soluções de solo sobre o índice de velocidade de germinação (IVG), a porcentagem de sementes normais, mortas, anormais, dormentes e o comprimento da parte aérea, do sistema radicular e da planta toda de B. brizantha cv. Marandu. Botucatu-SP, 2005

\begin{tabular}{|c|c|c|c|c|c|}
\hline \multirow{2}{*}{ Tratamento } & \multirow{2}{*}{ IVG } & Normal & Morta & Anormal & Dormente \\
\hline & & \multicolumn{4}{|c|}{$(\%)$} \\
\hline Água destilada & $10,53 \mathrm{~b}$ & $79,75 \mathrm{a}$ & $7,00 \mathrm{a}$ & $1,25 \mathrm{ab}$ & $12,00 \mathrm{a}$ \\
\hline Solução solo de pastagem & $11,10 \mathrm{~b}$ & $85,50 \mathrm{a}$ & $5,50 \mathrm{a}$ & $0,00 \mathrm{~b}$ & $9,00 \mathrm{a}$ \\
\hline Solução solo de mata & $10,86 \mathrm{~b}$ & $81,75 \mathrm{a}$ & $7,75 \mathrm{a}$ & $0,00 \mathrm{~b}$ & $10,50 \mathrm{a}$ \\
\hline Solução PEG (pastagem) & $16,93 \mathrm{a}$ & $80,75 \mathrm{a}$ & $7,00 \mathrm{a}$ & $0,00 \mathrm{~b}$ & $12,25 \mathrm{a}$ \\
\hline Solução PEG (mata) & $15,10 \mathrm{a}$ & $76,50 \mathrm{a}$ & $8,50 \mathrm{a}$ & $2,50 \mathrm{a}$ & $12,50 \mathrm{a}$ \\
\hline $\mathrm{F}_{\text {tratamento }} \ldots$ & $13,07 * *$ & $1,05^{\mathrm{ns}}$ & $0,59^{\mathrm{ns}}$ & $4,23 *$ & $0,27^{\mathrm{ns}}$ \\
\hline $\mathrm{CV}(\%)$ & 12,51 & (7, 7,89 & 40,66 & 145,04 & 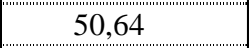 \\
\hline d.m.s. & 2,43 & 9,61 & 4,38 & 1,64 & 8,59 \\
\hline \multirow{3}{*}{ Tratamento } & \multicolumn{4}{|c|}{ Comprimento da parte aérea $(\mathrm{cm})$} & \\
\hline & \multicolumn{4}{|c|}{ Dias após a Instalação } & \\
\hline & 2 & 3 & 4 & 5 & \\
\hline Água destilada & $0,06 \mathrm{a}$ & $0,86 \mathrm{a}$ & $1,42 \mathrm{a}$ & $2,04 \mathrm{ab}$ & \\
\hline Soluç̧ão solo de pastagem & $0,14 \mathrm{a}$ & $0,72 \mathrm{a}$ & $1,34 \mathrm{a}$ & $2,19 \mathrm{a}$ & \\
\hline Soluç̧ão solo de mata & $0,00 \mathrm{a}$ & $0,56 \mathrm{a}$ & $1,34 \mathrm{a}$ & $2,10 \mathrm{ab}$ & \\
\hline Solução PEG (pastagem) & $0,28 \mathrm{a}$ & $0,61 \mathrm{a}$ & $0,95 \mathrm{~b}$ & $1,25 \mathrm{c}$ & \\
\hline Solução PEG (mata) & $0,29 \mathrm{a}$ & $1,00 \mathrm{a}$ & $0,95 \mathrm{~b}$ & $1,61 \mathrm{bc}$ & \\
\hline $\mathrm{F}_{\text {tratamento }}$ & $1,26^{\mathrm{ns}}$ & $0,86^{\mathrm{ns}}$ & $5,42 * *$ & $6,40 * *$ & \\
\hline $\mathrm{CV}(\%)$ & 148,87 & 52,57 & 16,60 & 16,94 & \\
\hline d.m.s. & 0,34 & 0,60 & 0,30 & 0,47 & \\
\hline \multirow{3}{*}{ Tratamento } & \multicolumn{4}{|c|}{ Comprimento da radícula $(\mathrm{cm})$} & \multirow{2}{*}{ Comprimento total } \\
\hline & \multicolumn{4}{|c|}{ Dias após a Instalação } & \\
\hline & 2 & 3 & 4 & 5 & $(\mathrm{~cm})$ \\
\hline Água destilada & $0,66 \mathrm{ab}$ & $1,71 \mathrm{a}$ & $2,64 \mathrm{~b}$ & $3,90 \mathrm{a}$ & $5,94 \mathrm{a}$ \\
\hline Solução solo de pastagem & $0,58 \mathrm{~b}$ & $1,81 \mathrm{a}$ & $2,84 \mathrm{ab}$ & 3,77 a & $5,96 \mathrm{a}$ \\
\hline Solução solo de mata & $0,37 \mathrm{~b}$ & $1,61 \mathrm{a}$ & $2,63 \mathrm{~b}$ & $3,62 \mathrm{a}$ & $5,69 \mathrm{a}$ \\
\hline Solução PEG (pastagem) & $0,79 a b$ & $1,88 \mathrm{a}$ & $3,25 \mathrm{ab}$ & $4,09 \mathrm{a}$ & $5,34 \mathrm{a}$ \\
\hline Solução PEG (mata) & $1,70 \mathrm{a}$ & 1,96 a & $3,40 \mathrm{a}$ & 4,56 a & $6,17 \mathrm{a}$ \\
\hline $\mathrm{F}_{\text {tratamento }}$ & $2,10^{\mathrm{ns}}$ & $1,11^{\mathrm{ns}}$ & $2,13^{\mathrm{ns}}$ & $1,16^{\mathrm{ns}}$ & $0,51^{\mathrm{ns}}$ \\
\hline $\mathrm{CV}(\%)$ & 86,56 & 14,57 & 16,39 & 148,87 & 15,34 \\
\hline d.m.s. & 1,07 & 0,36 & 0,73 & 0,34 & 1,35 \\
\hline
\end{tabular}

Médias seguidas de mesma letra na coluna não diferem estatisticamente entre si a 5\% de probabilidade pelo teste $\mathrm{t}$.

ns - não-significativo; $*$ - significativo a $5 \%$; $\mathrm{e}^{* *}$ - significativo a $1 \%$.

Pode-se observar que o IVG não foi afetado pelas diferentes soluções de solo utilizadas, em comparação à aplicação da água destilada. Os valores de IVG encontrados no tratamento com solução de solo da mata foram estatisticamente inferiores aos do PEG (mata). Esse resultado não pode ser atribuído a efeitos alelopáticos, uma vez que o IVG do tratamento de água destilada apresentou-se baixo, assim como a porcentagem de germinação $(59,5 \%)$.

A porcentagem de germinação da guanxuma não foi afetada pelos tratamentos testados. As soluções de solo da pastagem e da mata apresentaram germinação na ordem de 61,5 e 62,0\%, respectivamente. A porcentagem de sementes dormentes foi reduzida em todos os tratamentos, em comparação com a aplicação de água destilada, indicando, talvez, que o potencial osmótico das soluções testadas levou à quebra de dormência das sementes; contudo, esse fato não se reverteu em aumento da germinação e sim da porcentagem de sementes mortas.

No estudo de crescimento das plântulas de S. rhombifolia (Tabela 3) notou-se que tanto 
a solução de solo da pastagem como a da mata atuaram de forma semelhante no crescimento radicular e na parte aérea de $S$. rhombifolia.

No período de crescimento compreendido entre 72 e 84 horas após a instalação dos tratamentos, ocorreu efeito deletério no crescimento radicular de $S$. rhombifolia, no tratamento com solução de solo da pastagem, o que evidencia que a redução do crescimento da radícula de S. rhombifolia não foi devido ao potencial osmótico da solução aplicada, uma vez que com a solução de PEG ocorreu crescimento maior das plântulas. Esses efeitos ficaram evidentes também no crescimento total das plântulas, mas não de forma estatística; tal fato se deveu aos efeitos benéficos verificados sobre o crescimento da parte aérea.

Segundo Souza Filho (2002), os efeitos da alelopatia sobre o alongamento da radícula podem afetar a capacidade competitiva das invasoras por fatores essenciais à sobrevivência, como água e nutrientes, tendo como principal conseqüência o aumento da produtividade e longevidade da pastagem, com reflexos positivos na redução dos custos de manutenção da pastagem.

Tabela 2 - Efeito de diferentes soluções de solo sobre o índice de velocidade de germinação (IVG), a porcentagem de sementes normais, mortas, anormais, dormentes e o comprimento da parte aérea, do sistema radicular e da planta toda de Panicum maximum cv. Tanzânia. Botucatu-SP, 2005

\begin{tabular}{|c|c|c|c|c|c|}
\hline \multirow{2}{*}{ Tratamento } & \multirow{2}{*}{ IVG } & Normal & Morta & Anormal & Dormente \\
\hline & & \multicolumn{4}{|c|}{$(\%)$} \\
\hline Água destilada & $5,83 \mathrm{~b}$ & $43,75 \mathrm{a}$ & $38,50 \mathrm{~b}$ & $1,50 \mathrm{ab}$ & $16,25 \mathrm{a}$ \\
\hline Solução solo de pastagem & $3,23 \mathrm{c}$ & $21,50 \mathrm{c}$ & $56,25 \mathrm{a}$ & $1,75 \mathrm{ab}$ & $20,50 \mathrm{a}$ \\
\hline Solução solo de mata & $3,38 \mathrm{c}$ & $29,00 \mathrm{bc}$ & $35,23 \mathrm{~b}$ & $6,50 \mathrm{a}$ & $29,25 \mathrm{a}$ \\
\hline Solução PEG (pastagem) & $8,54 \mathrm{a}$ & $46,50 \mathrm{a}$ & $31,00 \mathrm{~b}$ & $0,00 \mathrm{~b}$ & $22,50 \mathrm{a}$ \\
\hline Solução PEG (mata) & 6,87ab & $38,25 \mathrm{ab}$ & $31,50 \mathrm{~b}$ & $3,50 \mathrm{ab}$ & 27,75 a \\
\hline $\mathrm{F}_{\text {tratamento }}$ & $10,18 * *$ & $8,21 * *$ & $8,33 * *$ & $1,72^{\mathrm{ns}}$ & $1,04^{\mathrm{ns}}$ \\
\hline $\mathrm{CV}(\%)$ & 25,68 & 20,32 & 18,68 & 143,11 & 43,56 \\
\hline d.m.s. & 2,16 & 10,96 & 10,84 & 5,72 & 15,13 \\
\hline \multirow{3}{*}{ Tratamento } & \multicolumn{4}{|c|}{ Comprimento da parte aérea $(\mathrm{cm})$} & \\
\hline & \multicolumn{4}{|c|}{ Dias após a Instalação } & \\
\hline & 2 & 3 & 4 & 5 & \\
\hline Água destilada & - & $0,70 \mathrm{a}$ & $1,30 \mathrm{a}$ & $1,30 \mathrm{a}$ & \\
\hline Solução solo de pastagem & - & $0,28 \mathrm{a}$ & $1,25 \mathrm{a}$ & $1,25 \mathrm{a}$ & \\
\hline Solução solo de mata & - & $0,45 \mathrm{a}$ & $1,10 \mathrm{a}$ & $1,10 \mathrm{a}$ & \\
\hline Solução PEG (pastagem) & - & $0,43 \mathrm{a}$ & $0,76 \mathrm{a}$ & $0,76 \mathrm{a}$ & \\
\hline Solução PEG (mata) & - & $0,18 \mathrm{a}$ & $0,63 \mathrm{a}$ & $0,63 \mathrm{a}$ & \\
\hline $\mathrm{F}_{\text {tratamento }}$ & - & $0,63^{\mathrm{ns}}$ & $1,26^{\mathrm{ns}}$ & $1,26^{\mathrm{ns}}$ & \\
\hline $\mathrm{CV}(\%)$ & - & 124,07 & 52,79 & 52,79 & \\
\hline d.m.s. & - & 0,76 & 0,80 & 0,80 & \\
\hline \multirow{3}{*}{ Tratamento } & \multicolumn{4}{|c|}{ Comprimento da radícula $(\mathrm{cm})$} & \multirow{2}{*}{ Comprimento total } \\
\hline & \multicolumn{4}{|c|}{ Dias após a Instalação } & \\
\hline & 2 & 3 & 4 & 5 & $(\mathrm{~cm})$ \\
\hline Água destilada & - & $0,73 \mathrm{a}$ & $1,17 \mathrm{a}$ & $2,04 \mathrm{ab}$ & $3,34 \mathrm{ab}$ \\
\hline Solução solo de pastagem & "3'-" & $0,55 \mathrm{a}$ & $1,30 \mathrm{a}$ & $2,32 \mathrm{a}$ & 3,57 a \\
\hline Solução solo de mata & - & $0,69 \mathrm{a}$ & $1,10 \mathrm{a}$ & 2,18 a & $3,28 \mathrm{ab}$ \\
\hline Solução PEG (pastagem) & - & $0,17 \mathrm{a}$ & $1,00 \mathrm{a}$ & $2,11 \mathrm{ab}$ & $2,86 \mathrm{ab}$ \\
\hline Solução PEG (mata) & - & $0,23 \mathrm{a}$ & $1,05 \mathrm{a}$ & $1,83 \mathrm{~b}$ & $2,46 \mathrm{~b}$ \\
\hline $\mathrm{F}_{\text {tratamento }}$ & - & $0,89^{\mathrm{ns}}$ & $0,62^{\mathrm{ns}}$ & $1,42^{\mathrm{ns}}$ & $1,49^{\mathrm{ns}}$ \\
\hline $\mathrm{CV}(\%)$ & - & 117,36 & 26,66 & 14,50 & 23,20 \\
\hline d.m.s. & - & 0,83 & 0,45 & 0,46 & 1,08 \\
\hline
\end{tabular}

Médias seguidas de mesma letra na coluna não diferem estatisticamente entre si a $5 \%$ de probabilidade pelo teste t. ns - não-significativo; * - significativo a $5 \%$; $\mathrm{e}^{* *}$ - significativo a $1 \%$. 
Tabela 3 - Efeito de diferentes soluções de solo sobre o índice de velocidade de germinação (IVG), a porcentagem de sementes normais, mortas, anormais, dormentes e o comprimento da parte aérea, do sistema radicular e da planta toda de Sida rhombifolia. Botucatu-SP, 2005

\begin{tabular}{|c|c|c|c|c|c|}
\hline \multirow{2}{*}{ Tratamento } & \multirow{2}{*}{ IVG } & Normal & Morta & Anormal & Dormente \\
\hline & & \multicolumn{4}{|c|}{$(\%)$} \\
\hline Água destilada & $11,97 \mathrm{~b}$ & $59,50 \mathrm{a}$ & $9,00 \mathrm{~b}$ & - & $31,50 \mathrm{a}$ \\
\hline Solução solo de pastagem & $11,71 \mathrm{~b}$ & $61,50 \mathrm{a}$ & $13,50 \mathrm{ab}$ & - & $25,00 \mathrm{~b}$ \\
\hline Solução solo de mata & $13,03 \mathrm{~b}$ & $62,00 \mathrm{a}$ & $13,50 \mathrm{ab}$ & - & $24,50 \mathrm{~b}$ \\
\hline Solução PEG (pastagem) & $12,03 \mathrm{~b}$ & $64,50 \mathrm{a}$ & $11,50 \mathrm{ab}$ & (3)"- & $24,00 \mathrm{~b}$ \\
\hline Solução PEG (mata) & $15,52 \mathrm{a}$ & $65,50 \mathrm{a}$ & $14,00 \mathrm{a}$ & - & $20,50 \mathrm{~b}$ \\
\hline $\mathrm{F}_{\text {tratamento }} \ldots$ & $5,92 * *$ & $0,58 \mathrm{~ns}$ & $1,57 \mathrm{~ns}$ & - & $3,45^{*}$ \\
\hline $\mathrm{CV}(\%)$ & 10,05 & 10,14 & 26,96 & - no & 17,20 \\
\hline d.m.s. & 1,95 & - 9,56 & 5,00 & - & 6,48 \\
\hline \multirow{3}{*}{ Tratamento } & \multicolumn{4}{|c|}{ Comprimento da parte aérea $(\mathrm{cm})$} & \\
\hline & \multicolumn{4}{|c|}{ Dias após a instalação } & \\
\hline & 48 & 60 & 72 & 84 & \\
\hline Água destilada & - & $0,46 \mathrm{c}$ & $2,78 \mathrm{ab}$ & $3,17 \mathrm{~b}$ & \\
\hline Soluç̧ão solo de pastagem & 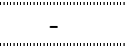 & $2,21 \mathrm{a}$ & $2,67 \mathrm{~b}$ & $2,97 \mathrm{~b}$ & \\
\hline Soluç̧ão solo de mata & (3) - & $2,49 \mathrm{a}$ & $3,07 \mathrm{a}$ & $3,57 \mathrm{a}$ & \\
\hline Solução PEG (pastagem) & 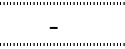 & $1,38 \mathrm{~b}$ & $1,76 \mathrm{c}$ & $2,16 \mathrm{c}$ & \\
\hline Solução PEG (mata) & - & $0,92 \mathrm{bc}$ & $1,32 \mathrm{~d}$ & $1,67 \mathrm{~d}$ & \\
\hline $\mathrm{F}_{\text {tratamento }}$ & - & $14,27 * *$ & $56,71 * *$ & $41,90 * *$ & \\
\hline $\mathrm{CV}(\%)$ & - & 30,29 & 8,50 & 8,86 & \\
\hline d.m.s. & - & 0,68 & 0,30 & 0,36 & \\
\hline \multirow{3}{*}{ Tratamento } & \multicolumn{4}{|c|}{ Comprimento da radícula $(\mathrm{cm})$} & \multirow{2}{*}{ Comprimento total } \\
\hline & \multicolumn{4}{|c|}{ Dias após a instalação } & \\
\hline & 48 & 60 & 72 & 84 & $(\mathrm{~cm})$ \\
\hline Água destilada & - & $0,79 \mathrm{~b}$ & $3,25 \mathrm{ab}$ & $3,61 \mathrm{ab}$ & $6,77 a b$ \\
\hline Solução solo de pastagem & - & $2,39 \mathrm{a}$ & $2,65 \mathrm{~b}$ & $2,89 \mathrm{c}$ & $5,86 \mathrm{~cd}$ \\
\hline Solução solo de mata & - & $2,90 \mathrm{a}$ & $3,23 \mathrm{ab}$ & $3,48 \mathrm{~b}$ & $7,06 \mathrm{a}$ \\
\hline Solução PEG (pastagem) & - & $2,86 \mathrm{a}$ & $3,55 \mathrm{a}$ & 4,08 a & $6,24 \mathrm{bc}$ \\
\hline Solução PEG (mata) & - & $2,37 \mathrm{a}$ & $3,06 \mathrm{ab}$ & $3,61 \mathrm{ab}$ & $5,16 \mathrm{~d}$ \\
\hline $\mathrm{F}_{\text {tratamento }}$ & - & $4,63 *$ & $2,62^{\mathrm{ns}}$ & $5,17 * *$ & $9,54 * *$ \\
\hline $\mathrm{CV}(\%)$ & - & 35,25 & 12,96 & 10,68 & 7,85 \\
\hline d.m.s. & - & 1,20 & 0,61 & 0,56 & 0,74 \\
\hline
\end{tabular}

Médias seguidas de mesma letra na coluna não diferem estatisticamente entre si a 5\% de probabilidade pelo teste t.

ns - não-significativo;* - significativo a $5 \%$; $\mathrm{e}^{* *}$ - significativo a $1 \%$.

Na Tabela 4 são apresentados os resultados dos efeitos das diferentes soluções de solo sob o teste de germinação de $P$. fuchsiaefolia em caixas gerbox e os efeitos sobre o crescimento das plântulas sob papel-toalha.

Em relação ao IVG, não ocorreram diferenças significativas entre as diferentes soluções de solo e a solução de água destilada, enquanto a solução de PEG (mata) apresentou decréscimo em relação à solução retirada da mata, porém não significativo. Para a porcentagem de germinação, apenas ocorreram diferenças significativas entre a solução de solo da pastagem e a solução de PEG (pastagem), a qual teve sua porcentagem de germinação reduzida. As soluções de PEG (pastagem) e PEG (mata) obtiveram valores de germinação na ordem de 64 e $72 \%$, respectivamente. As soluções de solo da mata, água destilada e pastagem obtiveram 86,5, 92 e 93\% de germinação, respectivamente.

Em relação à porcentagem de sementes dormentes e de sementes mortas, os tratamentos com solução de PEG foram os que proporcionaram as maiores porcentagens, comparadas com as demais soluções testadas. 
Tabela 4 - Efeito de diferentes soluções de solo sobre o índice de velocidade de germinação (IVG), a porcentagem de sementes normais, mortas, anormais, dormentes e o comprimento da parte aérea, do sistema radicular e da planta toda de Peschiera fuchsiaefolia. Botucatu-SP, 2005

\begin{tabular}{|c|c|c|c|c|c|}
\hline \multirow{2}{*}{ Tratamento } & \multirow{2}{*}{ IVG } & Normal & Morta & Anormal & Dormente \\
\hline & & \multicolumn{4}{|c|}{$(\%)$} \\
\hline Água destilada & $3,98 \mathrm{a}$ & $92,00 \mathrm{a}$ & $5,50 \mathrm{~b}$ & - & $2,50 \mathrm{c}$ \\
\hline Solução solo de pastagem & 3,84 a & $93,00 \mathrm{a}$ & $5,50 \mathrm{~b}$ & 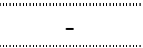 & (1,50 c \\
\hline Solução solo de mata & $2,93 a b$ & $86,50 \mathrm{ab}$ & $9,00 \mathrm{ab}$ & - & $4,50 \mathrm{bc}$ \\
\hline Solução PEG (pastagem) & $2,74 \mathrm{ab}$ & $64,00 \mathrm{c}$ & $17,50 \mathrm{a}$ & "3+"'- & $18,50 \mathrm{a}$ \\
\hline Solução PEG (mata) & $1,47 \mathrm{~b}$ & $72,00 \mathrm{bc}$ & $14,00 \mathrm{ab}$ & 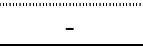 & $14,00 \mathrm{ab}$ \\
\hline $\mathrm{F}_{\text {tratamento }} \ldots$ & $4,11 *$ & $6,14 * *$ & $3,01^{\mathrm{ns}}$ & - & $4,58 *$ \\
\hline $\mathrm{CV}(\%)$ & 33,21 & 12,76 & 59,58 & 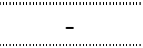 & $\begin{array}{l}86,58 \\
86\end{array}$ \\
\hline d.m.s. & 1,50 & 15,68 & 9,25 & 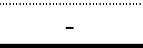 & 10,70 \\
\hline \multirow{3}{*}{ Tratamento } & \multicolumn{4}{|c|}{ Comprimento da parte aérea $(\mathrm{cm})$} & \\
\hline & \multicolumn{4}{|c|}{ Dias após a instalação } & \\
\hline & 15 & 17 & 19 & 21 & \\
\hline Água destilada & - & - & - & - & \\
\hline Solução solo de pastagem & - & - & - & 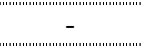 & \\
\hline Solução solo de mata & - n & - & - & 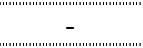 & \\
\hline Solução PEG (pastagem) & - & - & - & 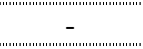 & \\
\hline Solução PEG (mata) & - & - & - & "- & \\
\hline $\mathrm{F}_{\text {tratamento }}$ & - & - & - & - & \\
\hline $\mathrm{CV}(\%)$ & - & - & - & - & \\
\hline d.m.s. & - & - & - & - & \\
\hline \multirow{3}{*}{ Tratamento } & \multicolumn{4}{|c|}{ Comprimento da radícula $(\mathrm{cm})$} & \multirow{2}{*}{ Comprimento total } \\
\hline & \multicolumn{4}{|c|}{ Dias após a instalação } & \\
\hline & 15 & 17 & 19 & 21 & $(\mathrm{~cm})$ \\
\hline Água destilada & $1,52 \mathrm{a}$ & $2,64 \mathrm{a}$ & $3,47 \mathrm{a}$ & $4,24 \mathrm{a}$ & - \\
\hline Solução solo de pastagem & $1,22 \mathrm{ab}$ & $2,16 \mathrm{ab}$ & $2,94 \mathrm{ab}$ & $3,79 \mathrm{ab}$ & - \\
\hline Solução solo de mata & 1,37 a & $2,45 \mathrm{a}$ & $3,31 \mathrm{a}$ & 4,31 a & - \\
\hline Solução PEG (pastagem) & $0,47 \mathrm{c}$ & $1,12 \mathrm{c}$ & $1,67 \mathrm{c}$ & $2,30 \mathrm{c}$ & - \\
\hline Solução PEG (mata) & 0,85 bc & $1,67 \mathrm{~b}$ & $2,57 \mathrm{~b}$ & $3,13 \mathrm{bc}$ & - \\
\hline $\mathrm{F}_{\text {tratamento }}$ & $7,01^{\mathrm{ns}}$ & $13,00^{\mathrm{ns}}$ & $9,41^{\mathrm{ns}}$ & $7,77^{\mathrm{ns}}$ & - \\
\hline $\mathrm{CV}(\%)$ & 29,41 & 17,01 & 16,76 & 17,00 & - n \\
\hline d.m.s. & 0,48 & 0,51 & 0,70 & 0,91 & 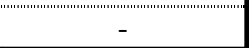 \\
\hline
\end{tabular}

Médias seguidas de mesma letra na coluna não diferem estatisticamente entre si a $5 \%$ de probabilidade pelo teste t.

ns - não-significativo; $*$ - significativo a $5 \% ; \mathrm{e}^{* *}$ - significativo a $1 \%$.

O estudo de crescimento de plântulas de $P$. fuchsiaefolia (Tabela 4) evidenciou que não houve nenhum dano devido à aplicação das diferentes soluções, tanto de mata como de pastagem.

Na Tabela 5 encontram-se os resultados dos efeitos das diferentes soluções de solo sobre o teste de germinação de $L$. sativa (alface) em caixas gerbox e dos efeitos no crescimento das plântulas sob papel-toalha.

Não houve efeito algum, nem promotor ou deletérico, das soluções testadas sobre o IVG, a porcentagem de germinação, a dormência, as sementes mortas e as plântulas anormais. Os valores obtidos nos tratamentos para germinação foram superiores a 94,5\%; a solução do solo sob mata apresentou a maior média: cerca de 96,5\% de germinação.

Com relação ao estudo de crescimento das plântulas de alface (Tabela 5), observaram-se efeitos deletérios pronunciados provocados pela solução de solo, tanto da mata como da pastagem, apenas na radícula das plântulas de alface e de forma mais intensa entre 72 e 84 horas após a instalação dos tratamentos, 
quando ocorreram diferenças estatísticas em relação às soluções de PEG. No que se refere à planta inteira, apenas a solução de solo da mata continuou mantendo os efeitos observados na parte aérea.

O melhor entendimento do modo de atuação dos compostos alelopáticos sobre o banco de sementes do solo pode auxiliar na escolha de espécies mais indicadas para renovação dos pastos, além de alertar sobre a necessidade de práticas agrícolas que minimizem os efeitos alelopáticos. Por meio dos dados obtidos neste experimento, pode-se inferir que em áreas de pastagem cultivada com $B$. brizantha $\mathrm{cv}$.
Marandu há mais de cinco anos a ocorrência de efeitos auto-alelopáticos sobre a germinação das sementes é desprezivel, favorecendo o estabelecimento de novas plantas de $B$. brizantha, oriundas do banco de sementes. No entanto, a utilização de Panicum maximum cv. Tanzânia como alternativa de renovação de pastagem em área anteriormente cultivada com B. brizantha cv. Marandu pode apresentar desvantagens, devido aos efeitos alelopáticos da $B$. brizantha, que podem interferir principalmente no processo de germinação das sementes de Panicum sp., prejudicando a formação uniforme do pasto, e, dessa forma, favorecer o surgimento de plantas daninhas.

Tabela 5 - Efeito de diferentes soluções de solo sobre o índice de velocidade de germinação (IVG), a porcentagem de sementes normais, mortas, anormais, dormentes e o comprimento da parte aérea, do sistema radicular e da planta toda de Lactuca sativa. Botucatu-SP, 2005

\begin{tabular}{|c|c|c|c|c|c|}
\hline \multirow{2}{*}{ Tratamento } & \multirow{2}{*}{ IVG } & Normal & Morta & Anormal & Dormente \\
\hline & & \multicolumn{4}{|c|}{$(\%)$} \\
\hline Água destilada & $47,13 \mathrm{a}$ & $95,00 \mathrm{a}$ & $3,50 \mathrm{a}$ & $1,50 \mathrm{a}$ & - \\
\hline Solução solo de pastagem & $47,60 \mathrm{a}$ & "'"95,50 a & $2,50 \mathrm{a}$ & $2,00 \mathrm{a}$ & 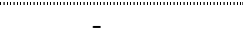 \\
\hline Solução solo de mata & $48,00 \mathrm{a}$ & $96,50 \mathrm{a}$ & $2,00 \mathrm{a}$ & 1, & - \\
\hline Soluçãa PEG (pastagem) & $45,13 \mathrm{a}$ & $\begin{array}{l}95,50 \mathrm{a} \\
95\end{array}$ & $3,50 \mathrm{a}$ & $1,00 \mathrm{a}$ & 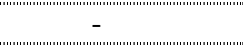 \\
\hline Solução PEG (mata) & $46,88 \mathrm{a}$ & $94,50 \mathrm{a}$ & $3,50 \mathrm{a}$ & $2,00 \mathrm{a}$ & '"'-"' - - \\
\hline $\mathrm{F}_{\text {tratamento }}$ & $1,21^{\mathrm{ns}}$ & $0,26^{\mathrm{ns}}$ & $0,83^{\mathrm{ns}}$ & $0,14^{\mathrm{ns}}$ & - \\
\hline $\mathrm{CV}(\%)$ & 4,29 & 3,06 & 51,64 & 138,82 & 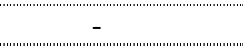 \\
\hline d.m.s. & '3, 3,03 & 4,40 & 2,33 & 3,35 & 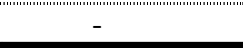 \\
\hline \multirow{3}{*}{ Tratamento } & \multicolumn{4}{|c|}{ Comprimento da parte aérea $(\mathrm{cm})$} & \\
\hline & \multicolumn{4}{|c|}{ Dias após a instalação } & \\
\hline & 48 & 60 & 72 & 84 & \\
\hline Água destilada & $0,26 \mathrm{bc}$ & $0,73 \mathrm{a}$ & $0,95 a b$ & $1,38 \mathrm{a}$ & \\
\hline Solução solo de pastagem & $0,22 \mathrm{c}$ & $0,69 a$ & $1,00 \mathrm{a}$ & $1,43 \mathrm{a}$ & \\
\hline Solução solo de mata & $0,00 \mathrm{~d}$ & $0,42 \mathrm{~b}$ & $0,90 \mathrm{ab}$ & $1,43 \mathrm{a}$ & \\
\hline Solução PEG (pastagem) & n & $0,46 \mathrm{~b}$ & $0,60 \mathrm{c}$ & $0,81 \mathrm{c}$ & \\
\hline Solução PEG (mata) & $0,29 \mathrm{~d}$ & $0,56 \mathrm{ab}$ & $0,85 \mathrm{~b}$ & $1,14 \mathrm{~b}$ & \\
\hline $\mathrm{F}_{\text {tratamento }}$ & $95,95 * *$ & $4,36^{*}$ & $12,89 * *$ & $12,06 * *$ & \\
\hline $\mathrm{CV}(\%)$ & 12,84 & 23,49 & 9,90 & 12,41 & \\
\hline d.m.s. & 0,05 & 0,20 & 0,13 & 0,23 & \\
\hline \multirow{3}{*}{ Tratamento } & \multicolumn{4}{|c|}{ Comprimento da radícula $(\mathrm{cm})$} & \multirow{2}{*}{ Comprimento total } \\
\hline & \multicolumn{4}{|c|}{ Dias após a instalação } & \\
\hline & 48 & 60 & 72 & 84 & $(\mathrm{~cm})$ \\
\hline Água destilada & $0,65 \mathrm{~b}$ & $0,78 \mathrm{c}$ & $0,94 \mathrm{~b}$ & $1,24 \mathrm{c}$ & $2,62 \mathrm{~b}$ \\
\hline Soluçãá solo de pastagem & $0,77 \mathrm{ab}$ & $1,06 \mathrm{ab}$ & $1,14 \mathrm{~b}$ & $1,43 \mathrm{c}$ & $2,86 \mathrm{~b}$ \\
\hline Solução solo de mata & $0,80 \mathrm{ab}$ & $0,88 \mathrm{bc}$ & $1,04 \mathrm{~b}$ & $1,40 \mathrm{c}$ & $2,83 \mathrm{~b}$ \\
\hline Solução PEG (pastagem) & 0,93 a & $1,03 \mathrm{ab}$ & $1,46 \mathrm{a}$ & $2,10 \mathrm{~b}$ & $2,88 \mathrm{~b}$ \\
\hline Solução PEG (mata) & $0,81 \mathrm{ab}$ & $1,18 \mathrm{a}$ & $1,66 \mathrm{a}$ & $2,48 \mathrm{a}$ & $3,61 \mathrm{a}$ \\
\hline $\mathrm{F}_{\text {tratamento }}$ & $3,18^{*}$ & $4,13 *$ & $13,13 * *$ & $23,48 * *$ & $4,91 * *$ \\
\hline $\mathrm{CV}(\%)$ & 14,33 & 15,87 & 13,28 & 12,60 & 11,47 \\
\hline d.m.s. & 0,17 & 0,24 & 0,25 & 0,33 & 0,51 \\
\hline
\end{tabular}

Médias seguidas de mesma letra na coluna não diferem estatisticamente entre si a $5 \%$ de probabilidade pelo teste t. ns - não-significativo;* - significativo a $5 \%$; $\mathrm{e}^{* *}$ - significativo a $1 \%$. 
Dentre as plantas daninhas avaliadas, S. rhombifolia mostrou maior sensibilidade a possiveis compostos alelopáticos da solução extraída do solo sob pastagem de $B$. brizantha cv. Marandu, em relação a P. fuchsiaefolia.

Os conhecimentos dos efeitos da alelopatia e suas interações inter e intra-específicas de plantas e microrganismos são de suma importância no contexto de qualquer ecossistema. Essas informações possibilitam ao pesquisador identificar possíveis causas do insucesso no estabelecimento e na persistência das pastagens, principalmente as consorciadas, propiciando a adoção de práticas de manejo que auxiliem na seleção de espécies promissoras, de forma a evitar prejuízos que possam ocorrer decorrentes desses efeitos. Entretanto, a aplicação da alelopatia como alternativa de controle de plantas daninhas em áreas de cultivo poderá minimizar a utilização de herbicidas e, conseqüentemente, diminuir o custo da exploração, além de evitar riscos de contaminação do meio ambiente (Wu et al., 1999; Rezende et al., 2003).

\section{LITERATURA CITADA}

ALMEIDA, A. R. P. Efeitos alelopáticos de espécies de Brachiaria Griseb sobre algumas leguminosas forrageiras tropicais. 1993. 73 f. Dissertação (Mestrado em Fisiologia e Bioquímica de Plantas) - Escola Superior de Agricultura "Luiz de Queiroz", Piracicaba, 1993.

BRASIL. Ministério da Agricultura e Reforma Agrária. Departamento Nacional de Produção Vegetal. Regras para análise de sementes. Brasília: 1992. 365 p.

CARVALHO, S. J. C. Caracterização dos efeitos alelopáticos de Brachiaria brizantha cv. Marandu, no estabelecimento das plantas de Stilosanthes guianensis var. Vulgaris e cv. Bandeirantes. 1993. 72 f. Dissertação (Mestrado em Zootecnia) - Universidade Federal de Viçosa, Viçosa, 1993.

CASTRO, D. M.; VELINI, E. D.; MARTINS, D. Avaliação de possíveis efeitos alelopáticos de Cyperus rotundus utilizando-se solo e solução do solo de áreas infestadas com a planta daninha. In: CONGRESSO BRASILEIRO DA CIÊNCIA DAS PLANTAS DANINHAS, 21., 1997, Caxambu. Resumos... Caxambu: SBCPD, 1997. p. 434.

EMPRESA BRASILEIRA DE PESQUISA AGROPECUÁRIA - EMBRAPA. Renovação de pastagens pela rotação com culturas anuais. Campo Grande: Embrapa - CNPGC, 1991. (Projeto de Pesquisa).

MAGUIRE, J. D. Speed of germination: aid in selection and evaluation for seedling emergence and vigor. Crop Sci., v. 2, n. 2 , p. $176-177,1962$.
PEREZ, S. C. J. G.; FANTI, S. C.; CASALI, C. A. Influência da luz na germinação de sementes de canafístula submetidas ao estresse hídrico. Bragantia, v. 60, n. 3, p. 155-166, 2001.

REZENDE, C. P. et al. Alelopatia e suas interações na formação e manejo de pastagens. B. Agropec., n. 54, p. 1-55, 2003.

RODRIGUES, L. R. A.; REIS, R. A. Estabelecimento de outras forrageiras em áreas de Brachiaria spp. In: SIMPÓSIO SOBRE MANEJO DA PASTAGEM, 11., 1994, Piracicaba. Anais... Piracicaba: FEALQ, 1994. p. 299- 325.

RODRIGUES, L. R. A.; ALMEIDA, A. R. P.; RODRIGUES, T. J. D. Alelopatia em forrageiras e pastagens. In: SIMPÓSIO SOBRE ECOSSISTEMA DAS PASTAGENS, 2., 1993, Jaboticabal. Anais... Jaboticabal: FAPESP, 1993. p. $100-129$.

SOUZA, F. H. D. Preparo de soluções neutras de tetrazólio. Comunicado Técnico, EMBRAPA-CNPGC, n. 51, p. 1-2, 1994.

SOUZA FILHO, A. P. S.; RODRIGUES, L. R. A.; RODRIGUES, T. J. D. Potencial alelopático de forrageiras tropicais: efeitos sobre invasoras de pastagens. Planta Daninha, v. 15, n. 1, p. 53-60, 1997.

SOUZA FILHO, A. P. S. Atividade potencialmente alelopática de extratos brutos e hidroalcoólicos de feijão-deporco (Canavalia ensiformis). Planta Daninha, v. 20, n. 3, p. 357-364, 2002.

SOUZA, L. S. Avaliação dos possíveis efeitos alelopáticos de diversas espécies de plantas daninhas sobre o crescimento inicial de eucalipto. 1994. 120 f. Dissertação (Mestrado em Agronomia) - Universidade Estadual Paulista, Botucatu, 1994.

STANIZIO, R. M.; LEITE, G. G.; VILELA, L. Efeito alelopático de Brachiaria brizantha cv. Marandu sobre o crescimento de plantas de quatro leguminosas forrageiras. In: REUNIÃO ANUAL DA SOCIEDADE BRASILEIRA DE ZOOTECNIA, 28., 1991, João Pessoa. Anais... João Pessoa: SBZ, 1991. p. 95.

SUÑÉ, A. D.; FRANKE, L. B.; SAMPAIO, T. G. Efeitos do condicionamento osmótico na qualidade fisiológica de sementes de Adesmia latifolia (Spreng.) Vog. Revista Brasileira de Sementes, v. 24, n. 1, p. 18-23, 2002.

VELINI, E. D. Evaluation of allelopathic effects of leguminous species, using leaf water extracts and soil solution. Tsukuba, Japan: 1996. 18 p. (Research Report)

VELINI, E. D.; TAKABAYASHI, M.; YOGO, Y. Uso de solução do solo para a avaliação dos possíveis efeitos alelopáticos de leguminosas utilizadas como adubos verdes. In: CONGRESSO BRASILEIRO DA CIÊNCIA DAS PLANTAS DANINHAS, 21., 1997, Caxambu. Resumos... Caxambu: SBCPD, 1997. p. 445.

WU, H. et al. Crop cultivars with allelopathic capability. Weed Res., v. 39, p. 171-180, 1999. 